No. $10-7$

\title{
The Sensitivity of Long-Term Interest Rates to Economic News: Comment
}

\author{
Michelle L. Barnes and N. Aaron Pancost
}

\begin{abstract}
:
Refet Gürkaynak, Brian Sack, and Eric Swanson (2005) provide empirical evidence that long forward nominal rates are overly sensitive to monetary policy shocks, and that this is consistent with a model where long-term inflation expectations are not anchored because agents must infer the central bank's inflation target from noisy interest rate movements. Using the same data, methodology, and model, we show that their empirical results are neither persistent nor robust to small changes in sample period or methodology. In addition, their theoretical results rely mainly on an ad hoc law of motion for the inflation target-imperfect information about the target plays only a small role in un-anchoring expectations in their model.
\end{abstract}

Keywords: inflation targeting, monetary regime, excess sensitivity, forward rates

\section{JEL Classifications: E31, E42, E52, E58}

Michelle L. Barnes is a senior economist and policy advisor and N. Aaron Pancost is a research associate, both in the research department of the Federal Reserve Bank of Boston. Their e-mail addresses are

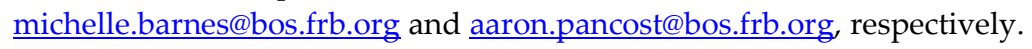

This paper, which may be revised, is available on the web site of the Federal Reserve Bank of Boston at http://www.bos.frb.org/economic/wp/index.htm.

The authors would like to thank Larry Ball, Refet Gürkaynak, Giovanni Olivei, and Eric Swanson for helpful comments. Any remaining errors are the responsibility of the authors.

The views expressed in here are those of the authors and do not necessarily reflect the views of the Federal Reserve Bank of Boston or the Federal Reserve System.

This version: July 26, 2010; first version May 5, 2010 
In a 2005 paper published in the American Economic Review, Refet Gürkaynak, Brian Sack, \& Eric Swanson (hereinafter GSS) provide both theoretical and empirical evidence that long-term inflation expectations are not well anchored in the United States, in part because the Federal Reserve does not have an explicit inflation target. GSS show that long forward rates, which can reasonably be taken as indicators of future expected short-term rates, are sensitive to current macroeconomic news, in sharp contrast to most standard macroeconomic models. GSS point out that although shocks in even highly backward-looking models must die out in at most a few years, empirically 10- and 15-year forward rates still move in response to current news announcements.

Perhaps the most surprising finding of the GSS paper, and certainly the most relevant from a monetary policy perspective, is that long forward rates actually respond negatively to surprise monetary actions. In other words, although a surprise tightening by the Fed does increase short-term interest rates, GSS find that from 1990 to 2002 surprise tightenings actually lowered expected future interest rates. The rationale they give for this result is that a surprise contraction reduces long-term inflation expectations. They derive a simple model of output and inflation expectations to argue that explicitly stating an inflation target would obviate this effect and anchor long-term expectations.

The GSS paper has become very influential in the inflation-targeting debate because of its strong results on both theoretical and empirical grounds: a very similar paper, based heavily on GSS, by Gürkaynak et al. (2007) (hereinafter GMLS), is one of the few proinflation-targeting papers not found wanting in Ball's 2010 analysis of the monetary regime literature.

We find that the empirical results for monetary policy shocks do not persist beyond a few days and that the same-day results depend heavily on eight particular dates for which monetary policy expectations cannot be accurately measured. We also show that GSS's interpretation of the model - that an explicitly stated inflation target anchors long-term inflation expectations - ignores the main driving force behind their result. In particular, the sensitivity of future nominal variables in their model is due almost entirely to the assumed sensitivity of the long-term inflation target to current shocks; explicitly stating the inflation target in their model does very little to anchor current expectations.

The rest of the comment is organized as follows. In Section 1 we replicate GSS's empirical findings and show that they are neither robust to small changes in methodology or sample period nor persistent beyond a few days. In Section 2 we describe the GSS model and show that its surprising results are due largely to an ad hoc assumption for the inflation target's law of motion, rather than because the inflation target is private information of the central bank. Section 3 concludes. 


\section{Empirical Results}

GSS show empirically that the long end of the forward yield curve is overly sensitive to current economic news. Their most powerful empirical result from the standpoint of monetary policy is that long forward rates actually respond negatively to current monetary policy surprises: a surprise downward shock to the federal funds rate lowers short-term interest rates, as it should, but also raises long forward yields (and, implicitly, expected future short-term interest rates). The estimated effect is statistically and economically significant.

One way to visualize the estimated effect of monetary policy surprises on the yield curve is given in Figure 1, which replicates Figure 3 of the GSS paper and the last row of Table 2 of the GMLS paper. We use the same data and estimation methodology as described by GSS. Specifically, we estimate the regressions

$$
\Delta f_{m t}=\alpha_{m}+\beta_{m} \varepsilon_{t}^{i}+\gamma_{m} \varepsilon_{t}^{X}+\eta_{m t} \quad m=1,2, \ldots, 15
$$

where $\Delta f_{m}$ is the one-day change in the $m$-year forward yield in basis points, $\varepsilon^{i}$ is the monetary policy shock, and $\varepsilon^{X}$ is a vector of other news shocks. The shocks are defined as the realized less the expected values, where expected monetary policy is inferred from changes in the current-month fed funds futures rates (as described by Kuttner 2001) and the other expectations are taken from the Money Market Services survey data. The monetary policy shocks are in basis points, while the other shocks are divided by their standard deviations, as in GSS. In Figure 1 we graph the 15 estimated $\beta_{m}$ coefficients (and 95 percent confidence intervals) across their respective maturities. From the figure, it is clear that we can reject the hypothesis that monetary policy shocks have no effect on forward rates at conventional levels.

We find that statistical significance at the long end is driven largely by how one treats eight particular monetary policy surprises from 1990 to 1994, in which the Federal Open Market Committee (FOMC) responded endogenously to unemployment reports (see footnote 9 of the GSS paper). The issue is that GSS, as well as most other papers in this vein, use daily data from the fed funds futures markets to measure monetary policy expectations, so it is impossible to disentangle the effect of the unemployment report on these days from the effect of the monetary policy action. In addition, even using the same assumptions as GSS, we find that the estimated effect does not persist: even if, on average, long forward yields do respond negatively to monetary policy shocks on the day of the shock, on average they also tend to revert back to their previous level two days later, so the three-day effect is indistinguishable from zero. 


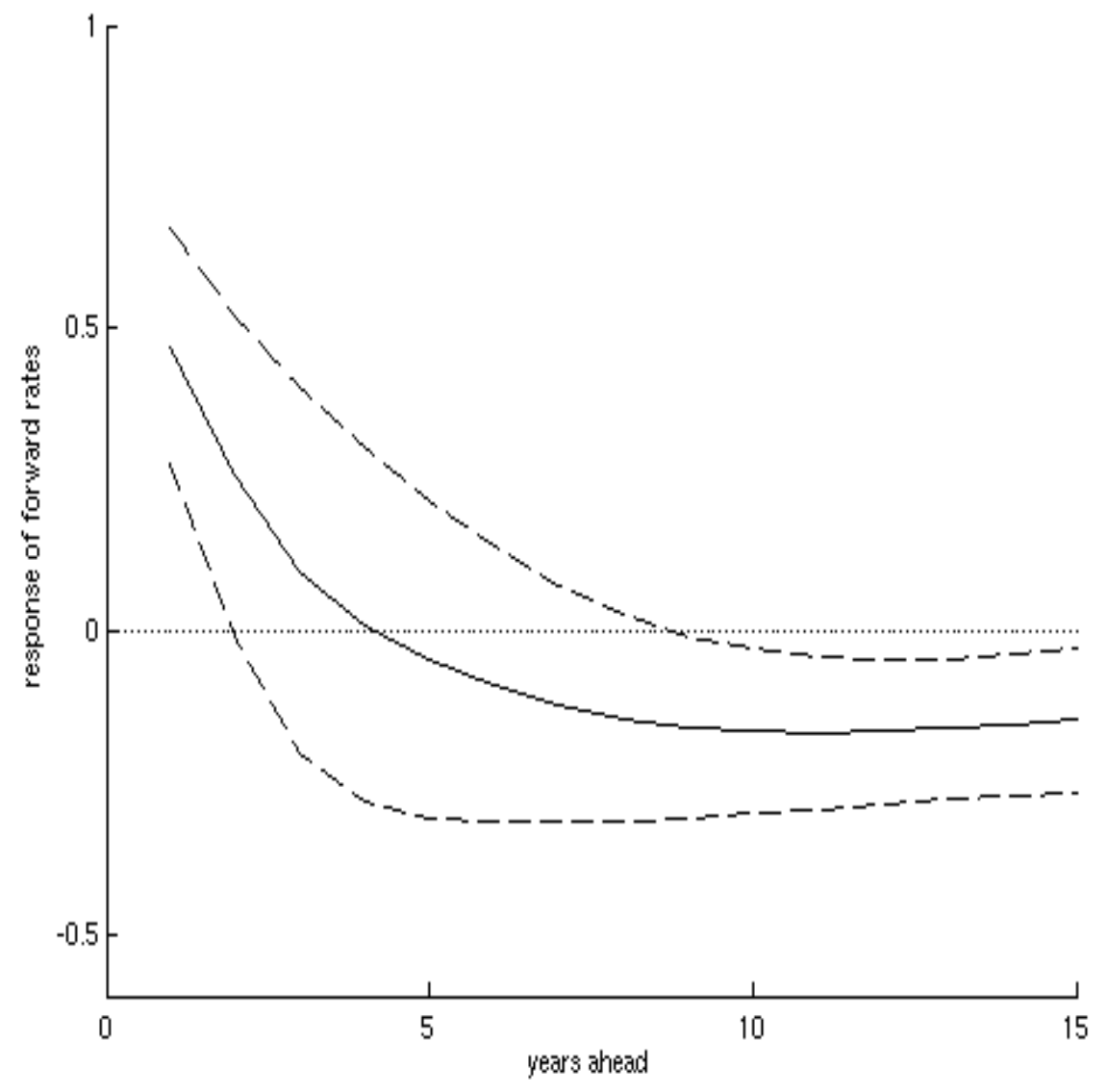

Figure 1: Response of Forward Rates to Monetary Policy Surprises

\subsection{Data Methodology}

In footnote 9 of their AER paper, GSS list various changes they apply to the daily change in the current fed funds futures rate in order to arrive at a measure of expected monetary policy. Their results are insensitive to all but one of these changes, a change that concerns monetary policy expectations on eight days when there was both an FOMC meeting and an employment report release on the same day. Since daily fed funds data are used to measure monetary policy shocks, on days such as these with multiple news releases, it is not possible to obtain a clean measure of the monetary policy shock. Note that with intra-daily data there would be no problem, because we could simply take the change from the previous night's close to directly after the employment release as the first shock, then the change from after the employment release to just after the FOMC action as the second shock. With 
daily data we only have each evening's close. ${ }^{1}$

Without better data this issue is to some extent unresolvable; GSS get around it by assuming that there was no surprise to the FOMC actions on these days. To do this they set the monetary policy shock variable to zero for these days - notice that this is essentially equivalent to dropping these eight observations entirely, since in these regressions almost all observations on the right-hand side are zero anyway (see Figure 3). In other words, GSS assume that although market participants may not have known what to expect before the employment release, after the release they knew exactly what the FOMC's response would be, all eight times. Another way around the problem would be to assume that the employment releases gave no information at all about future monetary policy; in this case we could safely use the end-of-day fed funds futures values to derive expected monetary policy.

Inspection of these eight dates reveals that all but one were either conference calls or intermeeting target adjustments. ${ }^{2}$ This means that they were unscheduled, and thus that market participants did not necessarily know that target changes were being considered. GSS's assumption of perfect foresight of monetary policy after the employment report means that agents not only knew exactly how big the target change would be, but also that a target change was coming at all. Perhaps more plausible is the idea that market participants saw the employment data, and then forecast the FOMC's target change for its next scheduled meeting. This would change the fed funds futures rate immediately after the employment release, to be sure, but it is unlikely that this movement would have been large relative to the surprise from a change in the target on a date when market participants were not expecting one at all. This suggests that we could also handle the problem by assuming that the employment releases gave no information at all about future monetary policy.

Neither assumption is particularly satisfying, and there does not seem to be a defensible middle ground. There is, however, an escape: we can easily restrict our sample to 1995 and

\footnotetext{
${ }^{1}$ Beechey and Wright (2009) use high-frequency intra-daily data to examine the same questions as GSS, and they reach similar conclusions (although they argue that monetary policy shocks only affect long-term inflation compensation). A complete analysis of their results is beyond the scope of the current paper, but we offer three observations. (1) The results are not directly comparable, as Beechey and Wright look only at the 5-10-year forward rate, rather than the whole yield curve as in GSS Figures $2 \& 3$ and our Figures $1 \& 2$. (2) Examining their online appendix, it appears that their long-end results are also highly dependent on the particular sample period chosen. Finally, (3) intra-daily data are really only useful in constructing the expectations measures, not in evaluating the effect of a shock to those expectations on yield outcomes. A very strong effect that can only be seen in intra-daily data because it disappears after 15 minutes is not one that should necessarily concern policymakers. More generally, the persistence of the estimated effects of news shocks on forward long-term yields and premia is a question that deserves more consideration from researchers - see Section 1.2.

${ }^{2}$ Only the last date (February 4th, 1994) corresponds to a scheduled FOMC meeting. In addition, there was no movement in the fed funds futures market on July 5th, 1991, so this date already has a zero for the policy surprise variable. The six remaining dates are all conference calls or unscheduled inter-meeting rate changes.
} 
later, which not only avoids these eight days but also avoids the period when the FOMC was not announcing target changes, but rather allowing markets to infer them from its subsequent open market activities (see GSS footnote 9).

Four alternative ways of handling the problem of these eight dates are graphed in Figure 2. In Figure 2(a) we simply treat the monetary surprise variable as we do on all other days; this is equivalent to assuming that agents did not update their estimated monetary policy action after the unemployment report came out. In Figure 2(b) we estimate the relationship on a sample period that does not include the eight affected days. In Figures 2(c) and 2(d) we estimate the relationship on the full sample from 1990 to April 2010, setting the monetary policy surprise variable to zero on these eight days as GSS do (2(c), no shock to monetary policy on the questionable days), or leaving it intact $(2(d)$, full shock to monetary policy on the questionable days). ${ }^{3}$

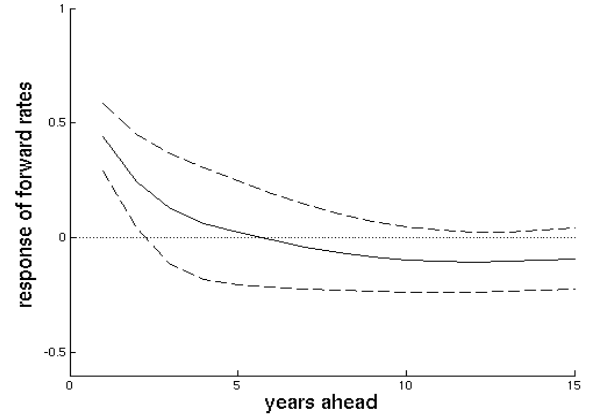

(a) Usual Surprise Variable on Eight Days

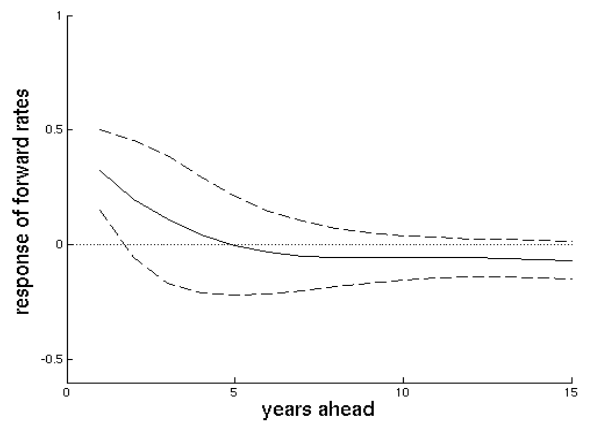

(b) Later Sample, Does Not Include Eight Days

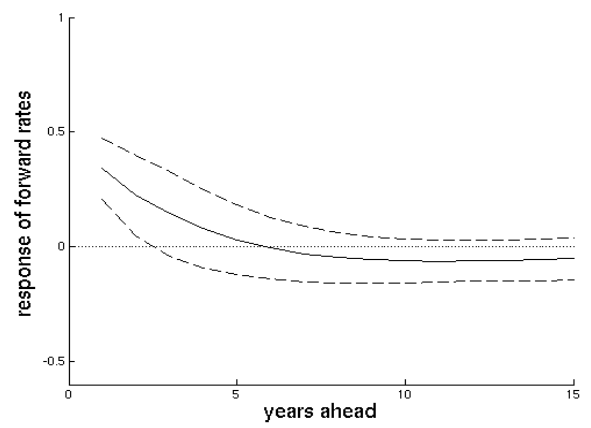

(d) Full Sample, Yes Surprise on Eight Days

(c) Full Sample, No Surprise on Eight Days

Figure 2: Alternative Estimates of Figure 1

In all four graphs the statistical significance of Figure 1 disappears, although just barely in Figure 2(c). Notice also that in all cases the estimated effect is also only about half as

\footnotetext{
${ }^{3}$ In GSS, the estimation sample ends in December 2002, so in these latter regressions we extend their sample period.
} 
strong as in Figure 1. Clearly, the strong negative response of long forward rates that GSS find is very dependent on how one treats these eight observations. In other words, only under the assumption of perfect foresight (conditional on the unemployment release) on the part of market participants on these eight specific days do we see the strong GSS empirical result. ${ }^{4}$

Another way of looking at these eight observations is given in Figure 3, where we show what exactly is going into the coefficient for the 10-year forward in Figure 1 (the scatterplot for other long forwards is qualitatively similar). Even if one believes these eight observations should be discarded or set to zero, it is clear that the negative coefficient is highly dependent on only a few observations. The sensitivity of these types of regressions to outliers deserves more consideration from researchers using these data.

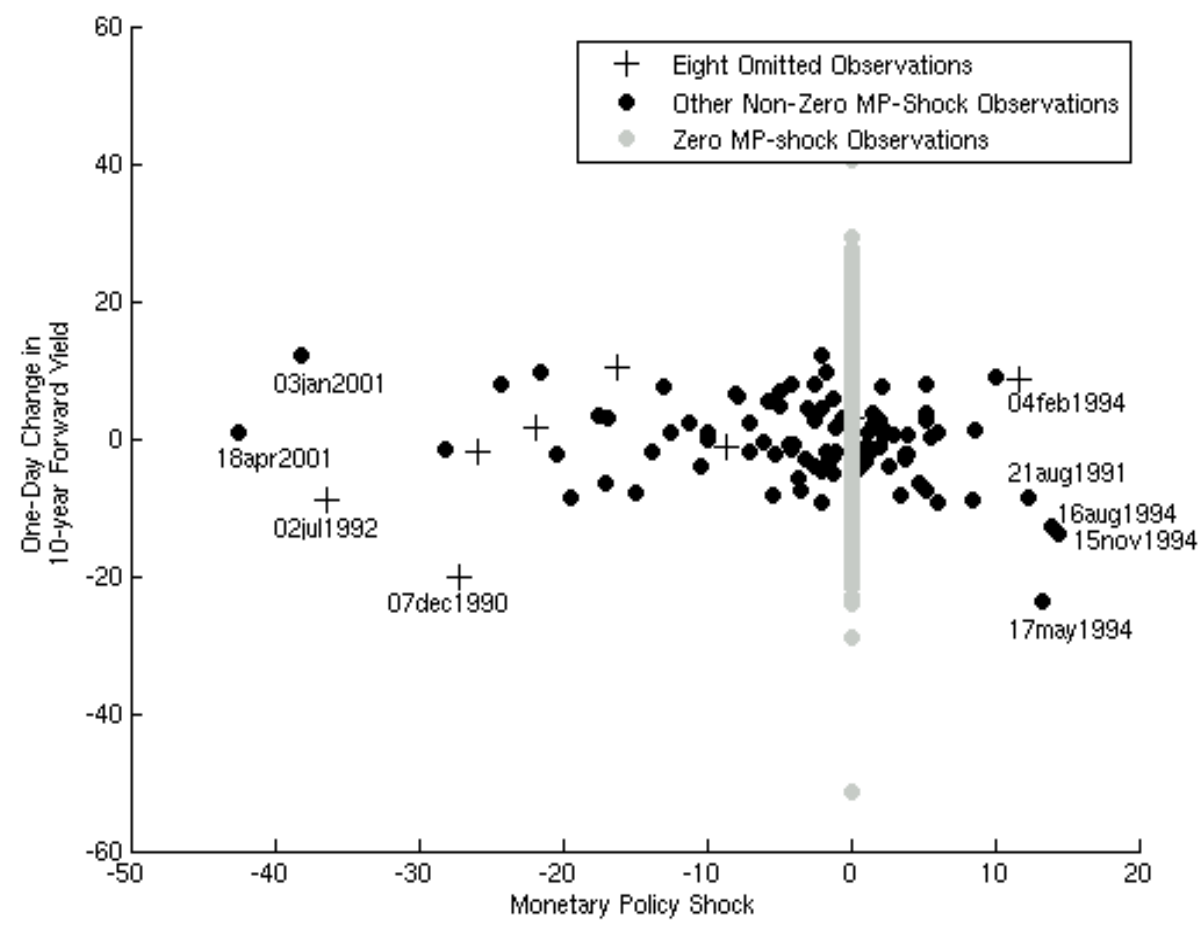

Figure 3: Scatterplot of 10-Year Forward Rate Changes vs. Monetary Policy Shock

Notwithstanding Figure 3, one thing to note about Figures 1 and 2 is that however one treats the employment-release dates, the coefficients at the long end tend to have a mass mainly below zero, whether it is significant at the 95 percent level or not. Thus, although we cannot strictly reject the hypothesis that the true coefficient lies above zero at conventional levels using this data, more generally the case for a negative response is stronger than the

\footnotetext{
${ }^{4}$ We welcome other ways of dealing with these eight observations, but even if another defensible way of handling the issue leads to the same strong result that GSS estimate, the fact remains that it does not exhibit subsample stability.
} 
case for a positive one. That being said, the estimated interest rate dynamics do not quite match the theoretical ones: in the original GSS model the strongest effect of an interest rate shock, other than the initial positive one, is at the short-to-medium end of the forward curve - see Figure 6. In fact, as we show in Section 2, the model predicts that the shortterm interest rate will drop below its steady state just a few periods after the shock, then rise, before it settles to a new steady state slightly below the older one. GSS consider only the short and long ends of their theoretical forward curve when comparing these theoretical dynamics to the empirical dynamics in Figure 1. In reality, the monetary policy surprise effect is almost squarely zero in the 2-7 year range-see Figure 1 or 2.

In addition, it is interesting to note that in successively later samples the coefficient at the long end appears to drift upwards toward zero. ${ }^{5}$ This is consistent with the hypothesis that inflation expectations were un-anchored in the early and middle 1990s, but have firmed up over time. ${ }^{6}$ In their 2007 paper, GMLS also estimate the regression on a later sample and show the negative long-end result disappearing (Table 2). They even point out, in footnote 21, that this may be because "long-term interest rates have gradually become better anchored in the United States." Yet the United States did not become an explicit inflation targeter during this period. What GLMS are suggesting, and as we will show using their model in Section 2, is that the important thing is not whether the target is explicitly announced but whether the central bank behaves as if it has one.

\subsection{Persistence}

Even if one believes that the one-day effect was or remains below zero, an important question is whether the effect persists over time (see footnote 1 above). A strong one-day effect that subsequently reverses itself may be evidence of market imperfection, but not of un-anchored long-term inflation expectations that could be anchored by explicitly stating an inflation goal. Using the same data methodology and sample period as GSS, we find that statistically the monetary policy surprise effects vanish after a few days.

In order to determine the persistence of the effects measured by GSS, we augment their baseline specification to include two lags of each surprise variable. In other words, we

\footnotetext{
${ }^{5}$ These results are available from the authors upon request.

${ }^{6}$ Of course, it is possible that components of the long forward nominal rate other than inflation expectations are responsible for the excess sensitivity. For example, Beechey (2006) finds that the largest negative movements at the long end are actually in term premia, rather than expected future short rates.
} 
estimate the regression

$$
\Delta f_{m t}=\alpha_{m}+\sum_{j=0}^{2} \beta_{j m} \varepsilon_{t-j}^{i}+\sum_{j=0}^{2} \gamma_{j m} \varepsilon_{t-j}^{X}+\eta_{m t} \quad m=1,2, \ldots, 15
$$

In Figure 4 we plot the sum of the three estimated coefficients $\left(\sum_{j=0}^{2} \hat{\beta}_{j m}\right)$ as well as a 95 percent confidence interval for the sum at each maturity. As above, in Figures 4(a) and 4(b) we restrict our attention to the original GSS sample period, including and excluding the eight questionable days, while in Figures 4(c) and 4(d) we extend the sample period out to April 2010. In all four cases, the effect at the long end of the yield curve is quite close to zero. This means that, although the individual lag coefficients are all insignificantly different from zero, ${ }^{7}$ the same-day coefficients are measured with enough error that we cannot reject the hypothesis that the sum of the three coefficients is zero. In other words, the data are consistent with the hypothesis that, although there is weak evidence that long forward yields respond negatively to surprise monetary policy actions on the day of the action, there is little to suggest that this effect lasts very long.

A potential criticism of this approach is that we are adding noise to the estimated effect by adding the lag coefficients, and that the noise is sufficient to mask a strong one-day effect. This argument is equivalent to questioning the power of the T-tests implied in Figure 4 after all, there are only about 90 (plus or minus eight) days in the 1990-to-2002 sample when the monetary policy surprise was nonzero. In order to show that the nonrejection results of Figure 4 are not due to lack of power in general, in Figure 5 we repeat the same exercise over the 1990-to-2002 sample for the Non-Farm Payrolls (155 days nonzero) and the Employment Cost Index (only 26 days nonzero) news shocks. For both variables, as for the monetary policy shock variable, all lags are insignificantly different from zero; however, for these two other variables the same-day effect is strong enough that it can still be detected after three days. Changing the number of lags in the regression, from two to as many as 10, does not significantly alter these conclusions.

Taken together, the results of this section imply that there is little evidence that long forward rates are excessively sensitive to monetary policy shocks. Small changes in sample period or data treatment from the GSS baseline case alter the statistical and economic significance of their findings, and even using their own assumptions, the persistence of the effect is in doubt.

\footnotetext{
${ }^{7}$ These results are available from the authors upon request.
} 


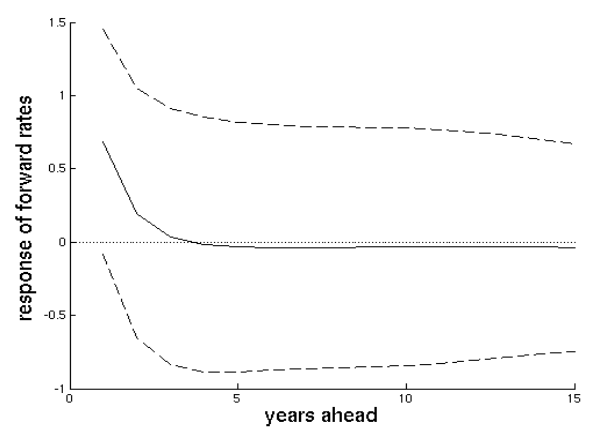

(a) Usual Surprise Variable on Eight Days

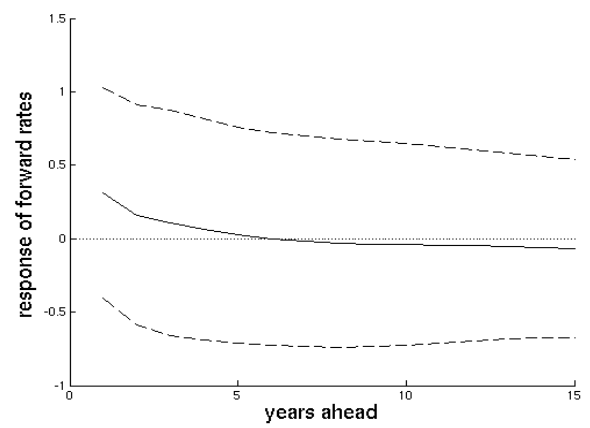

(c) Full Sample, No Surprise on Eight Days

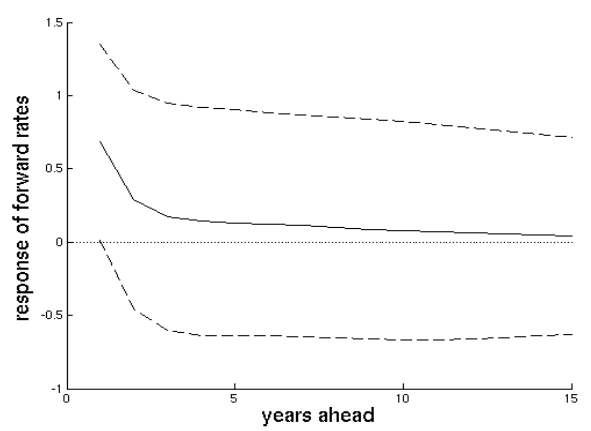

(b) Later Sample, Does Not Include Eight Days

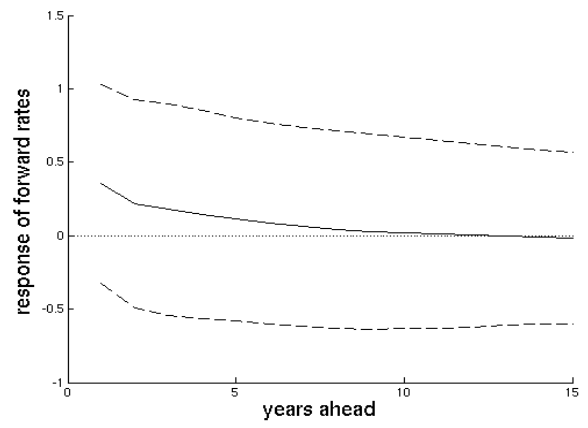

(d) Full Sample, Yes Surprise on Eight Days

Figure 4: Alternative Estimates of Figure 2 Using Sums of Lag Coefficients

\section{Theoretical Results}

In their conclusion, GSS argue that "the most plausible explanation for the observed term structure behavior is that the private sector has adjusted its expectations of the long-run level of inflation in response to these macroeconomic and monetary policy surprises." However, we demonstrate below that agents in their model are not adjusting their expectations primarily in response to such shocks, but rather in response to their knowledge of how the central bank will vary its target. In particular, if the GSS model is modified to have a known target, it remains the case that monetary policy shocks will lower longer-term yields. Furthermore, if we allow the central bank to have a fixed but unknown inflation target instead of specifying the target as slowly but continually changing in response to actual inflation as in GSS, then present monetary surprises have no impact on future rates. Since it is not uncertainty about the inflation objective that is driving the long-term yield response in GSS, it is hard to argue that GSS's model provides support for an explicit inflation objective. 


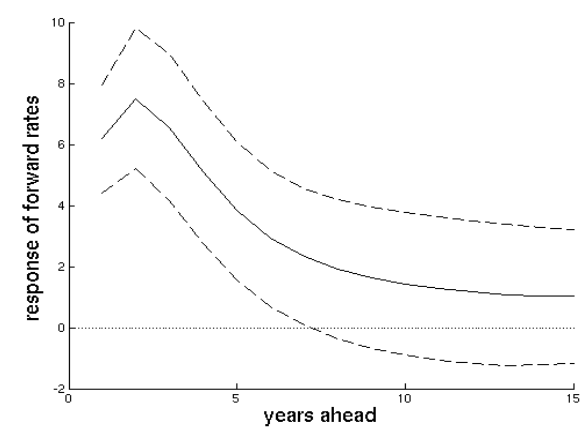

(a) Non-Farm Payrolls

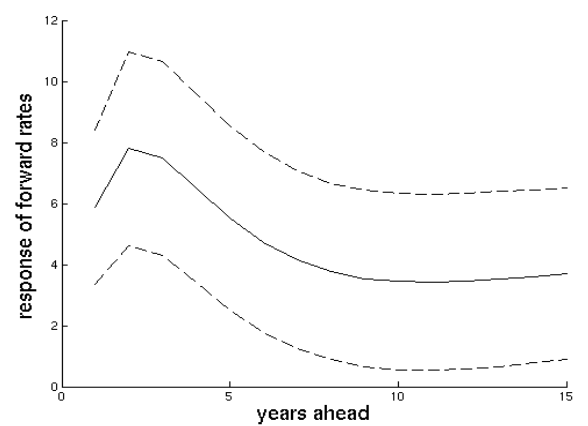

(b) Employment Cost Index

Figure 5: Sums of Lag Coefficients for ECI and Non-Farm Payrolls (1990-2002 Sample)

The dynamics of inflation and output in the GSS model are given by

$$
\begin{aligned}
& \pi_{t}=\mu_{\pi} E_{t} \pi_{t+1}+\left(1-\mu_{\pi}\right) A_{\pi}(L) \pi_{t}+\gamma y_{t}+\varepsilon_{t}^{\pi} \\
& y_{t}=\mu_{y} E_{t} y_{t+1}+\left(1-\mu_{y}\right) A_{y}(L) y_{t}-\beta\left(i_{t}-E_{t} \pi_{t+1}\right)+\varepsilon_{t}^{y}
\end{aligned}
$$

where $\pi$ is inflation, $y$ is the real output gap, the $\mu$ parameters determine the degree of forward-looking behavior on the part of agents, and the lag polynomials $A_{\pi}(L)$ and $A_{y}(L)$ govern the backward-looking dynamics of the model. The model is closed with interest rate and inflation target equations

$$
\begin{aligned}
i_{t} & =(1-c)\left[\bar{\pi}_{t}+a\left(\bar{\pi}_{t}-\pi^{*}\right)+b y_{t}\right]+c i_{t-1}+\varepsilon_{t}^{i} \\
\pi_{t}^{*} & =\pi_{t-1}^{*}+\theta\left(\bar{\pi}_{t}-\pi_{t-1}^{*}\right)+\varepsilon_{t}^{\pi^{*}}
\end{aligned}
$$

where $i$ is the short-term interest rate, $\bar{\pi}$ is a four-period moving average of realized inflation, and $\pi^{*}$ is the central bank's inflation target. Agents do not know the current $\pi^{*}$, nor can they observe the shocks $\varepsilon^{\pi^{*}}$ or $\varepsilon^{i}$. Instead they have an estimate of the current inflation target $\hat{\pi}^{*}$, which they update whenever the actual short rate $i$ deviates from their expected $\hat{i}$ (which they derive using Equation 5):

$$
\hat{\pi}_{t}^{*}=\hat{\pi}_{t-1}^{*}+\theta\left(\bar{\pi}_{t}-\hat{\pi}_{t-1}^{*}\right)-\kappa\left(i_{t}-\hat{i}_{t}\right) .
$$

Because agents faced with an unexpected short rate cannot tell whether it is due to a shock to $\varepsilon^{\pi^{*}}$ or $\varepsilon^{i}$, they move their estimate $\hat{\pi}^{*}$ only part of the way towards the $\pi^{*}$ implied by the unexpected $i$. Notice, however, that because the long-term inflation target is a function of current inflation (through $\bar{\pi}$ ), anything that moves current inflation will move the longterm target. This in turn will move the long-term values of all nominal variables in the model 
$\left(\pi, \pi^{*}, \hat{\pi}^{*}\right.$ and $\left.i\right)$. This, as we show in detail below, is why even without any uncertainty at all about the long-term inflation goal, in the GSS model expected future inflation and interest rates will respond to current economic shocks.

To see this more clearly, in Figure 6 we graph the impulse response functions of the GSS model against the same model, in which we allow agents to know the central bank's inflation target with certainty (in other words, we have replaced Equation 7 with $\hat{\pi}_{t}^{*}=\pi_{t}^{*}$ ). In our graphs below we use all the same parameters as GSS, except where noted.

Notice that the two interest rate dynamics in Figure 6 are virtually identical: in particular (third row, third column) the short-term rate responds to interest rate shocks in opposite directions at different ends of the yield curve, as GSS claim the data support. Thus, the main driver of their result is not the unknown state of the inflation target but rather the fact that the target moves (however slowly) in response to current inflation: a shock to the short rate today will lower inflation for some time to come, even if it has nothing to do with a target change. Because the target is assumed to respond to current inflation, this will bring the target down over time; the short rate simply follows it. Just as a negative shock to the target means a lower target and a lower short rate in the future, a positive shock to the short rate today means a lower target in the future and thus a lower short rate in the future. Uncertainty about the value of the target plays little role.

It is worth noting that in the body of their paper (page 433) GSS explain these dynamics: "...as inflation in the economy falls in response to both the monetary tightening and the fall in expectations of inflation, the central bank's target $\pi^{*}$ begins to fall as well. In the long run, the short-term nominal interest rate and inflation return to lower levels than where they began." In addition, in their 2007 paper GMLS also make the point implicitly, by graphing (as we have done here) both the perfect and imperfect information cases.

Knowing that the interest rate dynamics of the model depend on how the central bank alters its target endogenously, it is worth asking whether the assumed central bank policy function is a reasonable approximation to reality. In their model, the central bank adjusts its target for inflation continuously, moving it every period a little bit closer to the actual path of inflation. No matter how small "a little bit" is, this is unlikely to be the way the FOMC determines its inflation target, and the authors offer no evidence that it does. Just as plausibly, the inflation target is fixed in the short run but changes in discrete jumps in response to political factors - for example, a new chairman of the FOMC, or a congressional mandate that the Federal Reserve become an inflation targeter. In the simplified model we are using, such considerations must be exogenous; they belong in the error term $\varepsilon^{\pi^{*}}$.

For example, a more realistic model would be one where agents do not know the target and cannot predict when it will change, but are aware that it may change exogenously. In 

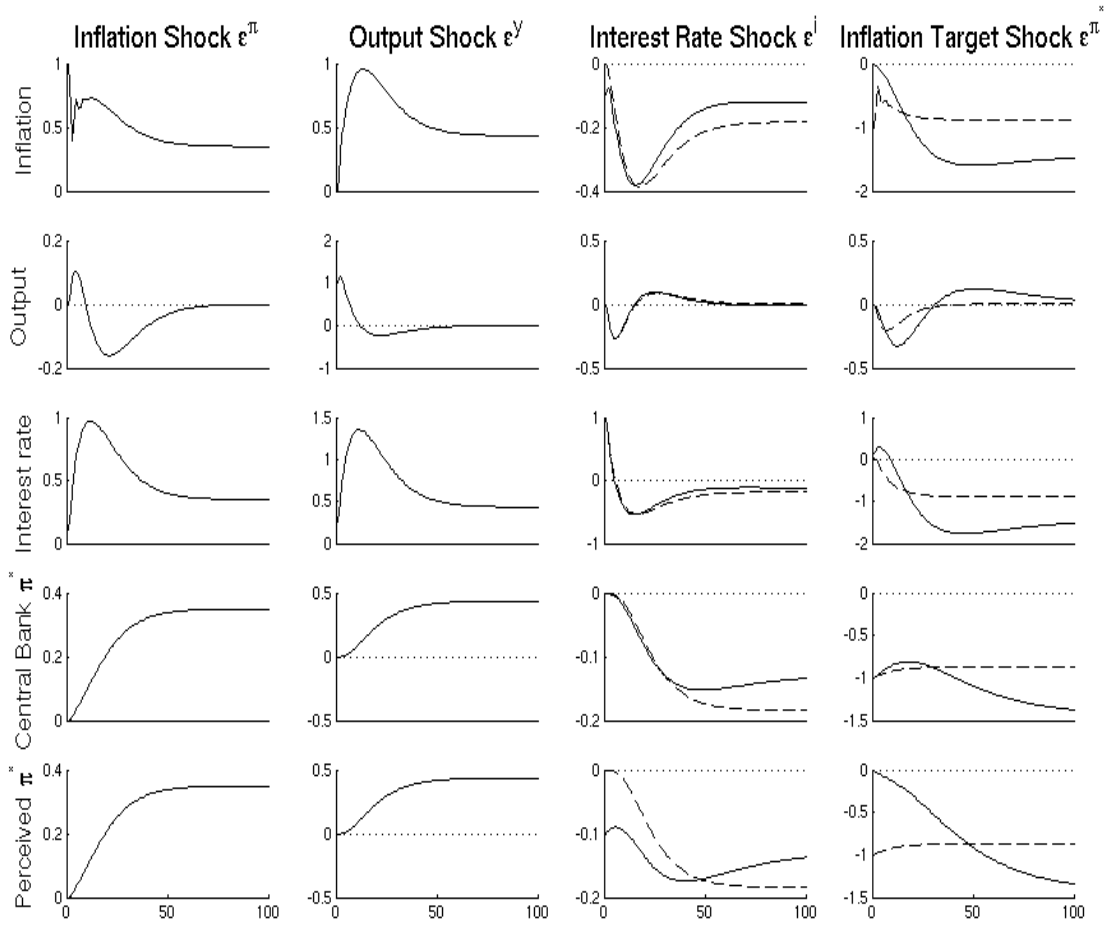

Baseline Model

Known Target

Figure 6: GSS Model vs. the Same Model with a Known Inflation Target

this model, the central bank's unknown inflation target does not change continuously in response to current inflation, although it does change through the exogenous error term $\varepsilon^{\pi^{*}}$. This is equivalent to the GSS model with $\theta=0$ instead of $\theta=0.02$. Notice, however, that we are still keeping $\kappa=0.1$ as in the original model; this is because although the inflation target does not change in response to every movement of current inflation, it may change exogenously (through $\varepsilon^{\pi^{*}}$ ) and thus agents are still not able to attribute unexpected interest rates to an interest-rate shock $\left(\varepsilon^{i}\right)$ or a target shock $\left(\varepsilon^{\pi^{*}}\right)$.

Again, we are not assuming in this model that the inflation target does not change over time, only that it does not change mechanically according to Equation 6 with $\theta>0$. It is entirely possible that the inflation target has changed, and if it has then it has most likely changed in response to current inflation; in particular the FOMC might ease its speed of adjustment to the target in the face of very large inflation shocks in order to dampen the potential effect on output. However, it is questionable that setting $\theta=.02$, or an even 

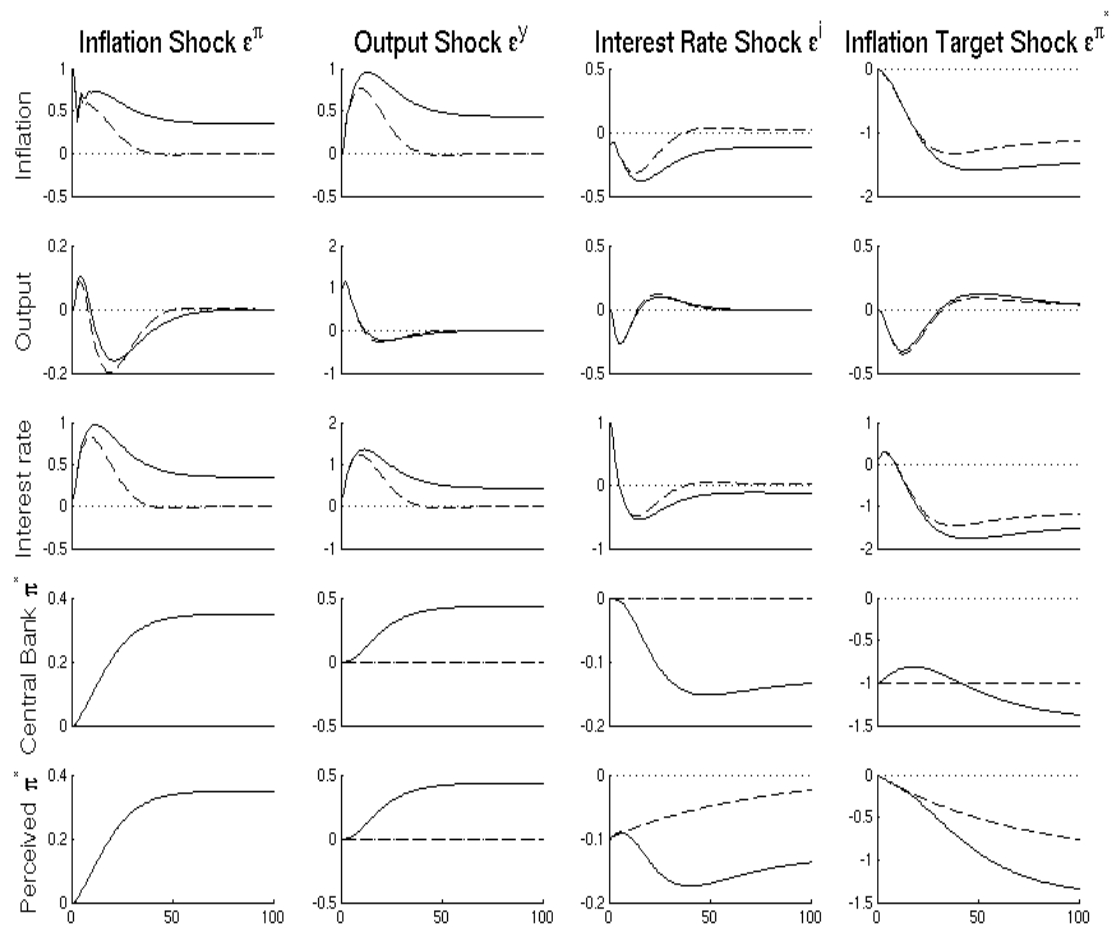

Baseline Model

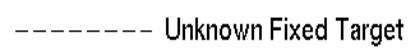

Figure 7: GSS Model vs. the Same Model with a Fixed but Unknown Inflation Target

smaller value, is the best way to model this behavior. Any value of $\theta$ greater than zero forces the central bank to adjust the long-term inflation target to every movement in inflation, no matter how small or temporary. This allows small shocks to inflation to "snowball" into large permanent changes, as we describe above. While we do not deny that the FOMC might change its target temporarily in the face of large output or inflation shocks, it is implausible that it would allow small shocks to systematically control its long-term inflation target.

The impulse response graphs for $\theta=0$ are given by the dashed lines in Figure 7, where the solid lines again trace out the baseline GSS model. In this model, even though the target is unknown, the short rate returns to its steady-state value after an interest rate shock. Notice, however, that this does not necessarily imply that long forward rates on the day of the shock will not respond. Although the original GSS paper examines only the actual dynamics of their model economy in response to shocks, more important for our purposes 
are the dynamics that agents expect to see as result of those shocks. ${ }^{8}$ The later GMLS paper makes this distinction clear in footnote 29 and by including Figures 3 and 4. The difference, though subtle, can be important. Thus, in Figure 8 we graph agent expectations at the time of the shock for the three models considered here: the GSS baseline model, the same model where the target is known with certainty, and the same model where the target is unknown but $\theta=0$.
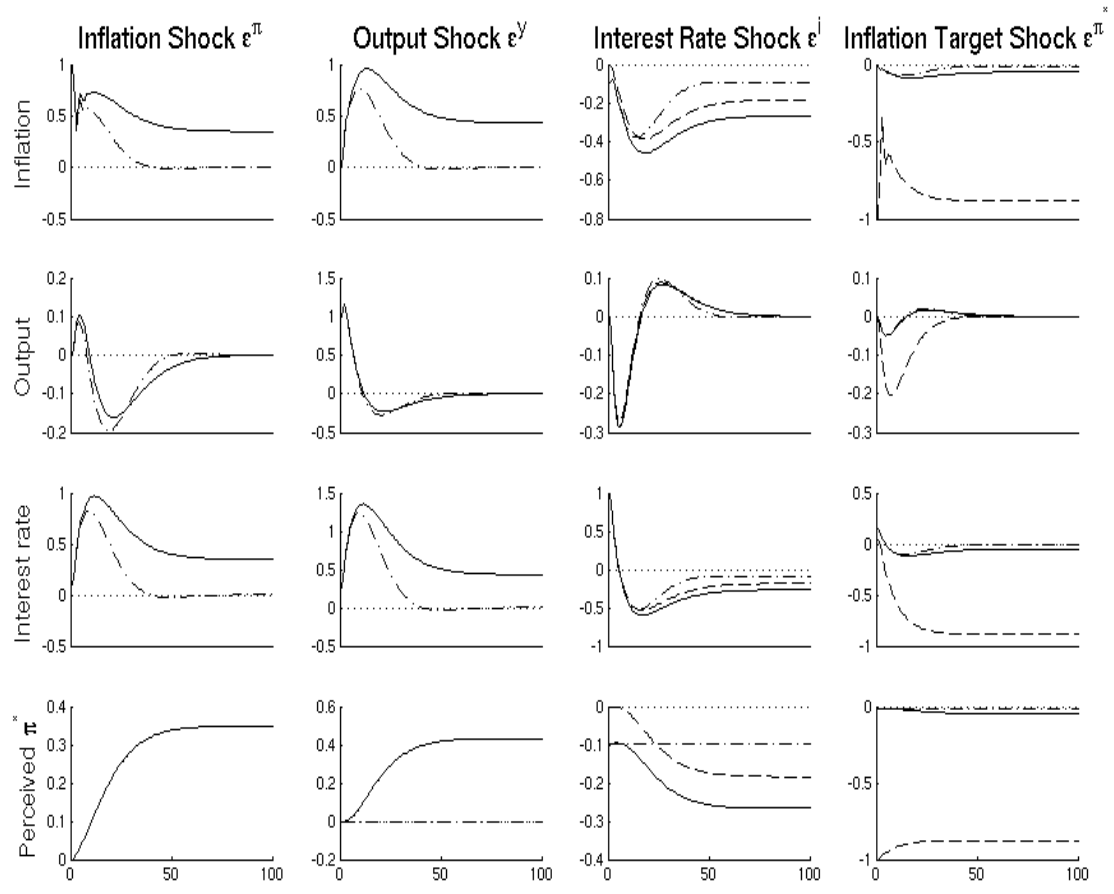

- Baseline Model

---Known Target

-.- Unknown Fixed Target

Figure 8: Expected Dynamics at $t=0$ in the GSS Model vs. Two Alternative Models

The first thing to take away from Figure 8 is that in all three cases, the expected future short rate is below the steady-state value. The largest effect on the expected future interest rate is in the baseline model, where the inflation target responds to current inflation $(\theta>0)$ and the target is unknown. Explicitly stating the target dampens this excess sensitivity somewhat, because it allows agents to distinguish correctly between the two shocks; however, it does not remove the sensitivity completely because of the way the target responds

\footnotetext{
${ }^{8}$ We thank Eric Swanson for pointing this out.
} 
"mechanically" to current inflation, as we point out above. An unknown target that agents know does not respond to current inflation moves expected future short rates substantially less than the baseline model; it is in this sense that the theoretical excess sensitivity of the original GSS model is driven mostly by the assumed law of motion for the inflation target, and not by the need for agents to infer the target.
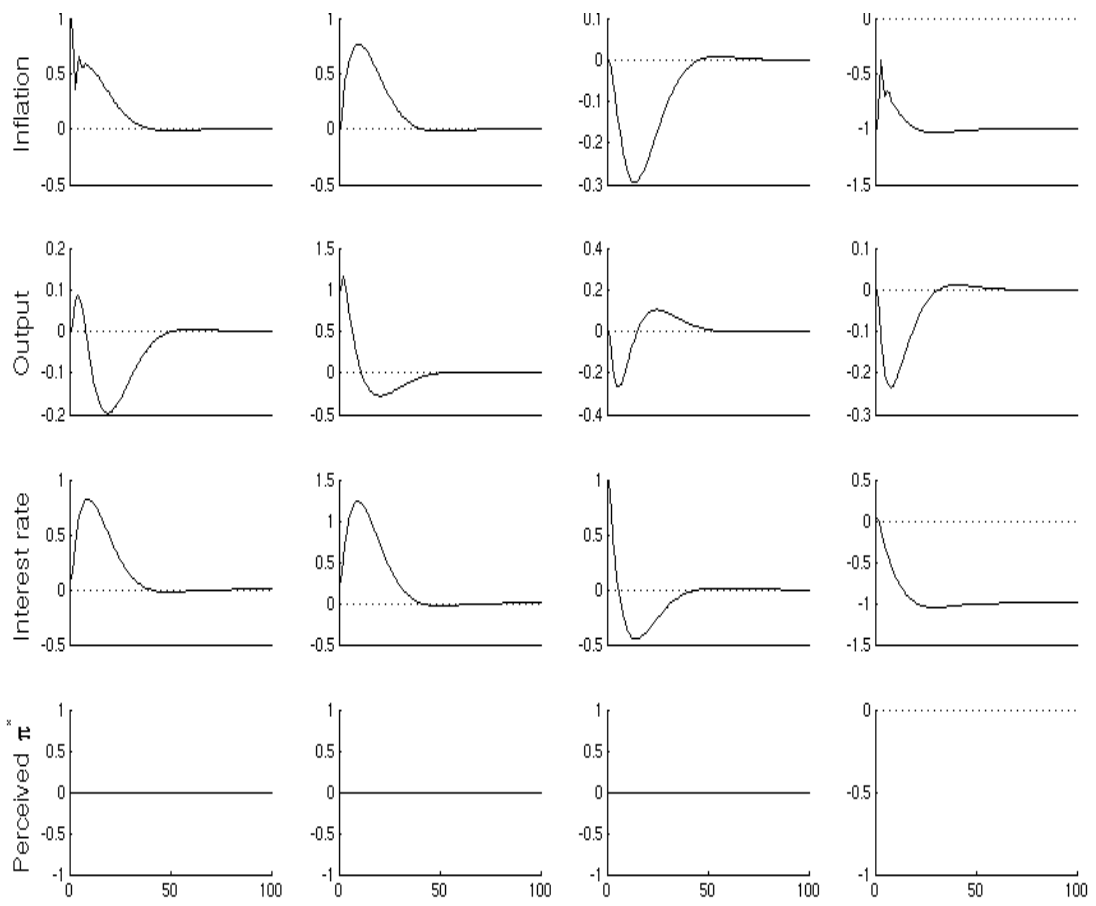

Known Fixed Target

Figure 9: Expected Dynamics at $t=0$ with a Known Fixed Target

In Figure 9 we plot the expected dynamics at the time of the shock in the case where the inflation target is known with certainty and $\theta=0$. In the GSS model, this is the only way to ensure that interest rate shocks do not move expected future interest rates. As with the unknown fixed target plotted in Figures 7 and 8, in this model long forward interest rates will not respond to inflation or output shocks either. In other words, the excess sensitivity of forward rates to these types of shocks must be accompanied by excess sensitivity to monetary policy shocks; if long forward rates are not sensitive to monetary policy surprises, then the GSS model predicts that they will not be sensitive to other shocks either. 
This last observation allows us a final empirical test of the GSS model. Given the result of Figure 2(b), that in later samples monetary policy shocks do not seem to move long forward rates, we can examine whether these rates are still overly sensitive to shocks to inflation or output news. The GSS model predicts that these sensitivities occur together; if in later samples monetary policy expectations are better anchored (perhaps because the FOMC signals its intentions more clearly ahead of time, or publishes its long-term inflation forecasts on a regular basis), then for the GSS model to truly fit the data, we must see the excess sensitivity of long forward rates to other economic news diminish as well.

In Figure 10 we plot the regression coefficients for the Institute of Supply Management (ISM) (formerly known as the National Association of Purchasing Management (NAPM)) Manufacturing Composite Index and Core-CPI news shocks for the later, 1995-to-2010, sample. Although monetary policy shocks do not move long forward rates over this sample, the coefficients for both of these other shocks are significantly different from zero at the long end of the yield curve. ${ }^{9}$ This suggests that something other than un-anchored expectations from an unknown inflation target is driving the observed excess sensitivity.

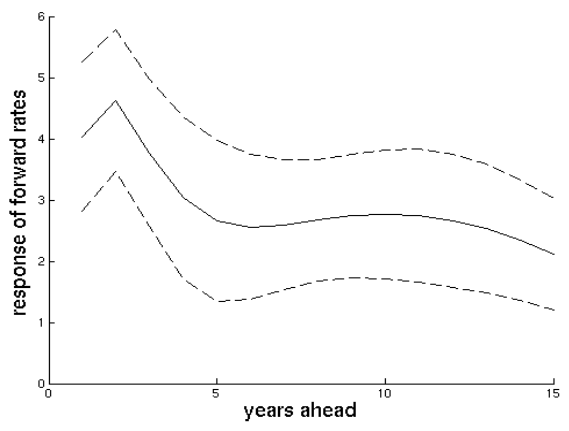

(a) NAPM(ISM)

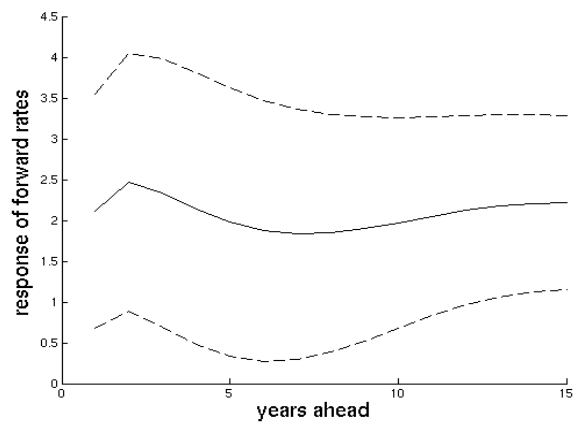

(b) Core CPI

Figure 10: Contemporaneous Coefficients for Core CPI and NAPM, 1995-to-2010 Sample

\section{Conclusion}

Unlike many other central banks in the developed economies, the Federal Reserve has a dual mandate to foster maximum employment consistent with stable inflation. Although the Fed has begun including long-term inflation projections with its policy statements, which some have likened to an implicit inflation target, many economists question whether an explicitly stated inflation target would not anchor long-term inflation expectations better, as it seems

\footnotetext{
${ }^{9}$ In addition, this excess sensitivity is robust to including lags and looking at the sum of the contemporaneous and lagged coefficients.
} 
to in some countries. ${ }^{10}$ Refet Gürkaynak, Brian Sack, and Eric Swanson (2005) offer empirical evidence that expectations are un-anchored in the United States, and theoretical evidence that this is consistent with agents having to infer the central bank's inflation target from noisy interest rate movements.

Using the same data, estimation methodology, and model as Gürkaynak, Sack, and Swanson (2005), we find that the evidence of un-anchored expectations in the data is unconvincing, and that the model in fact supports a different conclusion: explicitly stating the central bank's inflation target will stabilize long-term expectations less than merely keeping an unknown target fixed in the short term. We hope that these results will move the inflationtargeting debate away from the question of an implicit versus explicit target and towards issues such as how to identify economic conditions that warrant an inflation-target change, and how to re-establish a preferred long-term target, once those conditions are gone. These are exciting avenues of future research to which we look forward.

\section{References}

Ball, Laurence. 2010. "The Performance of Alternative Monetary Regimes." Handbook of Monetary Economics (forthcoming).

Beechey, Meredith. 2006. "A Closer Look at the Sensitivity Puzzle: the Sensitivity of Expected Future Short Rates and Term Premia to Macroeconomic News." Board of Governors of the Federal Reserve System (U.S.) Finance and Economics Discussion Series 2007-06.

Beechey, Meredith J., and Jonathan H. Wright. 2009. "The High-Frequency Impact of News on Long-Term Yields and Forward Rates: Is It Real?" Journal of Monetary Economics, 56(4): 535 - 544 .

Beechey, Meredith J., Benjamin K. Johannsen, and Andrew Levin. 2008. "Are Long-Run Inflation Expectations Anchored More Firmly in the Euro Area than in the United States?" Board of Governors of the Federal Reserve System (U.S.) Finance and Economics Discussion Series 2008-23.

Gürkaynak, Refet, Andrew Levin, and Eric Swanson. 2006. "Does Inflation Targeting Anchor Long-Run Inflation Expectations? Evidence from Long-Term Bond Yields in the US, UK and Sweden." C.E.P.R. Discussion Papers 5808.

\footnotetext{
${ }^{10}$ See for example Güurkaynak, Levin, and Swanson (2006) and Beechey, Johannsen, and Levin (2008).
} 
Gürkaynak, Refet S., Andrew N. Marder, Andrew T. Levin, and Eric T. Swanson. 2007. "Inflation Targeting and the Anchoring of Inflation Expectations in the Western Hemisphere." Federal Reserve Bank of San Francisco Economic Review, 25 - 48.

Gürkaynak, Refet S., Brian Sack, and Eric Swanson. 2005. "The Sensitivity of LongTerm Interest Rates to Economic News: Evidence and Implications for Macroeconomic Models." The American Economic Review, 95(1): 425-436.

Kuttner, Kenneth N. 2001. "Monetary Policy Surprises and Interest Rates: Evidence from the Fed Funds Futures Market." Journal of Monetary Economics, 47(3): 523 - 544. 